\title{
Nitrogênio não proteico em substituição ao farelo de soja na dieta de vacas F1 Holandês $x$ Zebu*
}

\section{Non-protein nitrogen used in replacement of soybean meal in the diet of F1 Holstein $x$ Zebu cows}

\author{
Ana Paula da Silva Antunes, ${ }^{* *}$ Vicente Ribeiro Rocha Júnior, ${ }^{* *}$ Gustavo Chamon de Castro Menezes, ${ }^{* *}$ \\ José Reinaldo Mendes Ruas, ${ }^{* * *}$ Vanice Mendes de Souza, ${ }^{* *}$ Lays Débora Silva Mariz, ${ }^{* * * *}$ \\ Jéssica Jordane Pereira Silva, ${ }^{* *}$ Deiyse Alves Silva**
}

\begin{abstract}
Resumo
Objetivou-se avaliar a inclusão de ureia em substituição do farelo de soja na dieta de vacas F1 Holandês x Zebu sobre parâmetros digestivos, produtivos e econômicos. Os níveis de substituição foram de 0, 33, 66 e 100\%. Foram utilizadas 8 vacas distribuídas em dois quadrados latinos $4 \times 4$, com 4 períodos de 18 dias. As amostras de alimentos, sobras, fezes e leite foram analisadas em laboratório e a análise econômica foi realizada por custeio direto. O consumo de matéria seca, proteína bruta, fibra em detergente neutro, carboidratos não fibrosos e nutrientes digestíveis totais, assim como a digestibilidade não foram influenciados pelos níveis de ureia nas dietas. Já a digestibilidade da proteína bruta aumentou linearmente. A produção de leite, ganho de peso, escore de condição corporal e a eficiência de uso do nitrogênio dietético não foram alterados, favorecendo economicamente o uso da maior inclusão de ureia nas dietas. Concluiu-se que a substituição total do farelo de soja pela ureia na dieta de vacas primíparas F1 Holandês x Zebu, não modifica os parâmetros digestivos, mantém o escore de condição corporal, permite o uso do nitrogênio de forma eficiente e é economicamente viável em relação ao uso de farelo de soja, para uma produção média de 10 kg de leite dia.
\end{abstract}

Palavras-chave: consumo, digestibilidade, eficiência, produção de leite.

\begin{abstract}
It was evaluated the inclusion of urea in place of soybean meal in the diet of cows F1 Holstein $\mathrm{x}$ Zebu on digestive, productive and economic parameters. The substitution levels of soybean meal by urea were $0,33,66$ and $100 \%$. It was used eight cows distributed in a two Latin squares $4 \times 4$, with four periods of 18 days. The feed, orts, milk and feces samples were analyzed in the laboratory and the economic analysis was performed by direct costing. The DM intake, CP, NDF, NFC and TDN as well as the digestibility were not influenced by levels of urea in the diets. The CP digestibility showed increasing linear effect. Milk production, gaining weight, body condition score and the dietary nitrogen use efficiency were unchanged, favoring the use of the economically most urea inclusion in diets. It was concluded that the total replacement of soybean meal by urea in the diet of primiparous cows F1 Holstein $x$ Zebu, does not modify the digestive parameters of animals, keeps the body condition score, allows the use of nitrogen efficiently and economically viable regarding the use of soybean meal to an average production of $10 \mathrm{~kg}$ of milk day.
\end{abstract}

Keywords: intake, digestibility, efficiency, milk production.

\section{Introdução}

O setor pecuário no Brasil apresenta modificações ao longo dos anos sempre buscando melhorar a taxa de conversão na produção de proteínas animais através da nutrição e genética. Mesmo com o crescimento populacional projetado para as próximas décadas, a adoção e implementação de novas tecnologias possibilitará o aumento da oferta de alimentos com diversificação e redução de custos (Lopes et al., 2007; Silva et al., 2015).

Neste sentido, o uso de animais de genética condizente com o ambiente tropical permite maior flexibilidade em resposta à produção de leite, dado a rusticidade e resistência ao ambiente, observado em vacas mestiças de genética Holandês/Zebu (Laguna et al., 2013; Ruas et al., 2009; Ruas et al., 2014; Santos et al., 2012). Assim, considerando-se a maior capacidade adaptativa dos animais mestiços, o uso de fontes e alimentos alternativos deve ser explorado ao máximo na dieta destes.

Nutricionalmente, os alimentos proteicos apresentam maior impacto nos custos de produção (Alves et al., 2010) e direcionam os esforços científicos para a busca de componentes dietéticos de similar resposta fisiológicas e produtiva às fontes cereais. O uso de compostos nitrogenados não proteicos (NNP), como a ureia, é uma alternativa para substituição das tradicionais fontes proteicas, como o farelo de soja, devido à capacidade dos micro-organismos ruminais de converter o NNP em proteína

\footnotetext{
*Recebido em 25 de agosto de 2015 e aceito em 8 de fevereiro de 2017.

**Universidade Estadual de Montes Claros (UNIMONTES), 39440-000, Janaúba, MG, Brasil. E-mail:gc.felix@hotmail.com Autor para correspondência.

*** Empresa de Pesquisa Agropecuária de Minas Gerais (EPAMIG), Janaúba, MG, Brasil.

****Universidade Federal de Viçosa (UFV), Viçosa, MG, Brasil.
} 
de alto valor biológico (Paixão et al., 2006; Alvarez et al., 2012; Antunes et al., 2014; Gonçalves et al., 2014).

Estudos de Broderick (2003) indicam que apenas cerca de 25\% a $35 \%$ do nitrogênio ingerido são excretados no leite, sendo a maioria do nutriente perdida na urina e nas fezes, representando prejuízo econômico. No que diz respeito ao custo, alternativas menos dispendiosas em relação às fontes de proteínas vegetais, como a ureia (Sinclair et al., 2012) pode permitir a redução da proteína dietética sem alterar o desempenho das vacas de leite (Sinclair et al., 2014).

Assim, objetivou-se por meio deste estudo avaliar a substituição parcial e total do farelo de soja pela ureia na dieta, sobre o desempenho produtivo e econômico de vacas F1 Holandês/ Zebu em lactação.

\section{Material e métodos}

Foram utilizadas oito vacas F1 Holandês/Zebu (H/Z), primíparas com aproximadamente $150 \pm 9$ dias de lactação ao início do experimento. O estudo foi aprovado pela Comissão de Ética em Experimentação e Bem Estar Animal da UNIMONTES (Parecer 044/2013). Utilizou-se dois quadrados latinos 4 X 4 simultâneos, compostos de quatro animais, quatro tratamentos e quatro períodos experimentais. O experimento foi realizado em 72 dias, sendo o período experimental de 18 dias com 15 dias iniciais para a adaptação dos animais às dietas e os três últimos dias para coleta de dados. Os tratamentos foram compostos por quatro dietas experimentais, formuladas para vacas com peso médio de $450 \mathrm{~kg}$ e produção de leite de $10 \mathrm{~kg} \mathrm{dia}^{-1}$. As dietas foram caracterizadas por níveis crescentes de inclusão do nitrogênio não proteico (NNP) em substituição ao farelo de soja, em 0, 33, 66 e 100\% de substituição, correspondendo a 0 , $0,92,1,84$ e $2,77 \%$ de PB na forma de NNP ou 0, 0,36, 0,73 e $1,1 \%$ de ureia na MS das dietas, ofertadas duas vezes ao dia, contendo $20 \%$ de concentrado e $80 \%$ de volumoso (silagem de sorgo) na base da MS das dietas.

A composição em ingredientes e química das dietas está demonstrada na tabela1. O consumo de matéria seca foi obtido pela diferença entre oferta e sobras após 24 horas de consumo ad libitum. Foram coletadas amostra de alimentos, sobras e fezes em cada período experimental, sendo posteriormente secas em estufa de ventilação forçada a $55^{\circ} \mathrm{C}$ por 72 horas. A produção de fezes foi estimada pelo indicador interno fibra em detergente ácido indigestível (FDAi). A quantificação da FDAi nas amostras de fezes, sobras, concentrados e forragem foram realizadas utilizando sacos Ankom F57 filter bags (Ankom Tech Corp, Fairport, NY). As amostras foram armazenadas em sacos filtros e incubadas por $288 \mathrm{~h}$ no rúmen de bovinos fistulados (Casali et al., 2008). Após a incubação o material remanescente foi lavado em água corrente e submetido a análise de FDA. O resíduo da análise da FDA das amostras incubadas foi considerado a FDAi. A produção fecal foi calculada pela divisão do total de FDAi excretada menos o consumo de FDAi do concentrado e forragem. As análises de matéria seca (MS), cinzas, extrato etéreo $(E E)$, proteína bruta $(P B)$, fibra em detergente neutro corrigido para cinzas e proteína (FDNcp), fibra em detergente ácido, compostos nitrogenados insolúveis em detergente neutro (NIDN) e em detergente ácido (NIDA), carboidratos não fibrosos (CNF) e lignina foram realizadas conforme descrito em Detmann et al. (2012). Os nutrientes digestíveis totais (NDT) foram calculados de acordo com o NRC (2001).
Tabela 1: Composição em ingredientes e composição química das dietas experimentais em \%, na base da matéria seca

\begin{tabular}{|c|c|c|c|c|}
\hline & \multicolumn{4}{|c|}{$\begin{array}{l}\text { Níveis de PB na forma de NNP na dieta } \\
\qquad(\%)\end{array}$} \\
\hline & 0 & 0,92 & 1,84 & 2,77 \\
\hline \multicolumn{5}{|c|}{ Ingredientes (\%) } \\
\hline Silagem de sorgo & 80 & 80 & 80 & 80 \\
\hline Farelo de soja & 6,74 & 4,49 & 2,24 & 0 \\
\hline Milho moído & 12,26 & 14,14 & 16,02 & 17,9 \\
\hline Ureia:SA* $(9: 1)$ & 0 & 0,36 & 0,73 & 1,1 \\
\hline Suplemento mineral & 1 & 1 & 1 & 1 \\
\hline \multicolumn{5}{|c|}{ Composição química (\%) } \\
\hline Matéria Seca & 46,7 & 46,7 & 46,6 & 46,6 \\
\hline Matéria Orgânica & 93,2 & 93,3 & 93,4 & 93,5 \\
\hline Proteína Bruta & 9,84 & 9,86 & 9,89 & 9,92 \\
\hline $\mathrm{NIDN}^{* *}$ & 0,45 & 0,43 & 0,50 & 0,48 \\
\hline $\mathrm{NIDA}^{* * *}$ & 0,02 & 0,02 & 0,02 & 0,02 \\
\hline Extrato Etéreo & 1,84 & 1,85 & 1,86 & 1,86 \\
\hline Carboidratos Totais & 81,6 & 81,4 & 81,2 & 82,0 \\
\hline Carboidrato não fibroso & 27,4 & 27,0 & 27,1 & 27,1 \\
\hline Fibra em detergente neutro & 55,9 & 55,9 & 55,8 & 55,7 \\
\hline $\mathrm{FDNcp}^{* * *}$ & 54,2 & 54,4 & 54,0 & 54,9 \\
\hline Fibra em detergente ácido & 31,7 & 31,6 & 31,5 & 31,3 \\
\hline Lignina & 3,17 & 3,15 & 3,12 & 3,10 \\
\hline Nutrientes Digestíveis Totais & 65,0 & 65,5 & 65,1 & 64,6 \\
\hline
\end{tabular}

"Sulfato de Amônia; "NIDN = Nitrogênio Insolúvel em Detergente Neutro; "'NIDA = Nitrogênio Insolúvel em Detergente Ácido; "'*"FDNcp = Fibra em Detergente Neutro corrigido para Cinzas e Proteína.

As vacas foram confinadas em baias individuais e ordenhadas mecanicamente com presença do bezerro ao pé, duas vezes ao dia e registrada a produção por período, nos últimos três dias de cada período. No último dia do período de coleta, amostras de leite em quantidade proporcional à produção de leite na ordenha da manhã e à tarde foram coletadas para análises dos teores de proteína, gordura e nitrogênio ureico no leite (NUL). Estas amostras foram acondicionadas em frascos com conservante Bronopol e enviadas para a Clínica do Leite - ESALQ/USP _ Campus Piracicaba, sendo as análises realizadas pelo método infra-vermelho. As produções de leite corrigidas para 3,5\% de gordura foram calculadas utilizando-se a equação proposta por Sklan et al. (1994). Os animais foram pesados em balança mecânica e seus escores de condição corporal (ECC) foram avaliados por um técnico no início e ao final de cada período experimental, de acordo com a metodologia descrita por Wildman et al. (1982).

A avaliação dos custos dos concentrados foi calculada multiplicando-se o consumo de concentrado por vaca pelo valor do $\mathrm{kg}$ de concentrado (calculado de acordo com sua composição e o preço de cada ingrediente), estimando-se as porcentagens da economia a partir dos valores encontrados (Rennó et al., 2008). A conversão alimentar foi calculada dividindo-se o consumo de $\mathrm{MS}(\mathrm{kg} / \mathrm{dia})$ pela produção de leite corrigida para $3,5 \%$ de gordura $\left(\mathrm{kg} \mathrm{dia}^{-1}\right)$. A eficiência alimentar foi calculada 
pela divisão da produção média de leite $\left(\mathrm{kg} \mathrm{dia}^{-1}\right)$ pela ingestão de MS ( $\mathrm{kg} \mathrm{dia}^{-1}$ ) (Valadares Filho et al., 2000). O cálculo da eficiência de utilização de nitrogênio foi realizado dividindo-se o N-total médio do leite pela ingestão média de nitrogênio da dieta (Broderick, 2003).

Os dados obtidos foram submetidos à análise de variância e regressão, utilizando-se o programa SISVAR (Ferreira, 2011), considerando-se $\alpha=0,05$.

\section{Resultados e discussão}

O aumento na concentração de NNP na dieta de vacas mestiças não foi capaz de modificar o consumo diário de nutrientes em $\mathrm{kg}$. No entanto, quando expressado em \% do peso corporal, o consumo de FDN decresceu $(P<0,05)$ com o aumento nos níveis de NNP das dietas, apresentando comportamento quadrático com um valor mínimo de consumo em $0,94 \%$ de PB na forma de NNP, demonstrados na Tabela 2. O consumo médio diário de MS foi de $13,3 \mathrm{~kg} \mathrm{dia}^{-1}$ ou 3,10 \% do peso corporal e estão condizentes com as recomendações propostas pelo NRC (2001) para vacas com produção média de $10 \mathrm{~kg}$ de leite dia ${ }^{-1}$. Não houve queda no consumo de CNF com a inclusão de NNP, todavia, observou-se que na MS total da dieta o componente proteico resultou em apenas $152 \mathrm{~g}$ de ureia no maior nível de inclusão.

Apesar de a ureia ser utilizada como controlador de consumo onde a maior inclusão tende a diminuir o consumo por bovinos (Lima et al., 2013), os resultados demonstram que animais mestiços, com produção de até $10 \mathrm{~kg}$ de leite dia $^{-1}$, respondem de forma produtiva similar ao uso de fontes proteicas cereais, permitindo lançar desafios nutricionais em maiores níveis do composto avaliado em dietas. Wilson et al. (1975) atribuíram a redução do consumo de MS da dieta a catabólitos intermediários do metabolismo da ureia, apenas quando a inclusão foi acima de $2,3 \%$.

A inclusão de ureia na dieta não influenciou $(P>0,05)$ as digestibilidades de MS, EE, FDN e CNF, no entanto a PB foi mais digestível $(P<0,05)$ com a elevação dos níveis de NNP nas dietas (Tabela 2). O aumento verificado na digestibilidade da PB pode ser explicado pelo fato de a ureia ser considerada $100 \%$ degradável no rúmen.

Todavia, efeitos positivos da inclusão de ureia na dieta de ruminantes sobre a digestibilidade dos nutrientes dependem da capacidade dos micro-organismos ruminais em assimilar os produtos finais da fermentação (Pessoa et al., 2009). Sabe-se, portanto, que a produção animal é definida pelo consumo voluntário, que determina a quantidade de nutrientes ingeridos e que a digestibilidade é uma descrição qualitativa do alimento.

Os pesos inicial e final, ganho de peso, escore da condição corporal, produção de leite e sua composição, assim como a conversão e eficiência alimentar e eficiência de uso do nitrogênio dietético pelas vacas não diferiram $(P>0,05)$ com o aumento da inclusão de NNP nas dietas (Tabela 3 ).
A evolução no segmento lácteo direcionou o mercado a valorizar o leite de maior qualidade, com maior composição em sólidos como a gordura. A concentração de gordura no leite de vacas alimentadas com NNP situa-se próximo de 3,5\% (Gonçalves et al., 2014), valor inferior ao encontrado neste trabalho (4,92\%). Provavelmente a alta proporção de volumoso utilizada nas dietas experimentais (80\%) associado ao atendimento das exigências para o crescimento microbiano, promoveram maior digestão da fibra, modificando a produção de ácidos graxos voláteis, aumentando a relação acetato:propionato e consequentemente, disponibilizando maior quantidade de acetato, precursor para formação de gordura no leite.

O teor de proteína do leite também não foi alterado em função dos níveis de inclusão de ureia na dieta das vacas $(P<0,05)$, entretanto, o NUL aumentou linearmente. Todavia, segundo relatos de Miglior et al. (2007) e Stoop et al. (2007), o NUL varia de $10,73-20,39 \mathrm{mg} \mathrm{dL}^{-1}$, sendo que valores médios acima de $16 \mathrm{mg} \mathrm{dL}^{-1}$ poderiam indicar excesso de proteína na dieta, deficiência na fermentação de carboidratos não fibrosos, e/ou desequilíbrio entre as disponibilidades de energia e nitrogênio dentro do rúmen. Assim, como pode ser verificado na tabela 3 , mesmo com a elevação do NUL, os valores encontrados foram relativamente baixos, podendo ser explicados também pelo nível de produção de leite e de ingestão de nitrogênio pelas vacas. Mucha \& Strandberg (2011) analisando dados de NUL de vários rebanhos de vacas holandesas constataram média de 13,6 mg $\mathrm{dL}^{-1}$ e Wanapat et al. (2009) avaliando o tratamento da palha de arroz com ureia observaram valores de 14,5 a $15,8 \mathrm{mg} \mathrm{dL}^{-1} \mathrm{de}$ NUL, sendo os valores mais altos para os tratamentos com ureia.

Apesar da baixa proporção de concentrado na dieta e consumo de $\mathrm{N}$, os animais responderam em produção de leite proporcional a seu consumo, com excreção de $\mathrm{N}$ no leite três vezes menor às obtidas com vacas de produção de leite diária de $34 \mathrm{~kg} \mathrm{dia}^{-1}$ (Sinclair et al., 2012), no entanto com mesma eficiência de uso do nitrogênio que indiretamente implica em menor perda econômica com a excreção. A eficiência de uso do nitrogênio é relevante quando o excesso do nutriente aumenta a demanda energética em 13,3 kcal de energia digestível por grama de $\mathrm{N}$ a ser excretado na forma de ureia (Broderick, 2003), podendo afetar o desempenho reprodutivo além da contaminação ambiental.

Vale destacar que os animais se encontravam no terço médio da lactação ao início do experimento (150 dias de lactação), isso permite utilizar componentes que minimize o custo dietético, seja através do aumento da concentração de ureia na dieta em até 5\% (Pina et al., 2006), ou até decrescer a concentração proteica na dieta (Sinclair et al., 2014) ponderando sobre o controle do escore corporal das vacas na secagem. Concomitante ao propósito econômico citado pelos autores, a Tabela 4 demonstra que o aumento do nível de NNP na dieta é inverso ao custo do concentrado. Rennó et al. (2008) relataram que a eficiência econômica é influenciada pelas quantidades e custos dos nutrientes utilizados dentro de um cenário específico de produção, e não somente ao nível de produção de leite. O uso da fonte proteica oriunda do farelo de soja elevou em $33,4 \%$ os custos em relação à sua ausência em $100 \%$ de sua substituição pela ureia. 
Tabela 2: Consumo e digestibilidade aparente dos nutrientes de dietas com níveis crescentes de NNP ofertadas a vacas F1 Holandês x Zebu, coeficientes de variação (CV), média geral e valor real de $\mathrm{P}$

\begin{tabular}{|c|c|c|c|c|c|c|c|}
\hline \multirow[b]{2}{*}{ Itens } & \multicolumn{4}{|c|}{ Níveis de PB na forma de NNP (\%) } & \multirow[b]{2}{*}{ CV (\%) } & \multirow[b]{2}{*}{ Média Geral } & \multirow[b]{2}{*}{$\mathrm{Pr}>\mathrm{Fc}$} \\
\hline & 0 & 0,92 & 1,84 & 2,77 & & & \\
\hline \multicolumn{8}{|c|}{ Consumo kg dia-1 } \\
\hline Matéria Seca & 13,2 & 13,1 & 13,2 & 13,8 & 8,28 & 13,3 & 0,5981 \\
\hline Proteína Bruta & 1,09 & 1,05 & 1,07 & 1,17 & 10,6 & 1,09 & 0,2239 \\
\hline Extrato Etéreo & 0,25 & 0,23 & 0,24 & 0,26 & 7,85 & 4,00 & 0,0740 \\
\hline Fibra em detergente neutro & 8,12 & 7,49 & 7,96 & 8,41 & 8,35 & 7,99 & 0,0803 \\
\hline Carboidratos não fibrosos & 4,10 & 3,90 & 4,20 & 4,10 & 8,04 & 4,08 & 0,0675 \\
\hline Nutrientes digestíveis totais & 7,44 & 6,53 & 6,44 & 6,43 & 15,2 & 6,71 & 0,1762 \\
\hline \multicolumn{8}{|c|}{ Consumo, $\%$ do peso corporal } \\
\hline Matéria Seca & 3,03 & 3,09 & 3,08 & 3,23 & 7,45 & 3,10 & 0,3810 \\
\hline Fibra em detergente neutro & 1,89 & 1,73 & 1,85 & 1,96 & 7,34 & * & 0,0240 \\
\hline \multicolumn{8}{|c|}{ Digestibilidade, \% } \\
\hline Matéria Seca & 56,4 & 56,1 & 56,4 & 56,5 & 7,68 & 56,4 & 0,9992 \\
\hline Proteína Bruta & 60,8 & 64,0 & 64,7 & 65,2 & 4,46 & ** & 0,0264 \\
\hline Extrato Etéreo & 58,5 & 55,5 & 63,1 & 67,6 & 20,3 & 61,2 & 0,2605 \\
\hline Fibra em detergente neutro & 50,6 & 47,0 & 50,5 & 50,6 & 11,1 & 49,7 & 0,4995 \\
\hline Carboidratos não fibrosos & 67,0 & 57,8 & 62,3 & 55,4 & 14,7 & 58,8 & 0,1666 \\
\hline
\end{tabular}

* $Y=2,1134-0,3049 x+0,0678 x^{2} ; R^{2}=0,86 ;{ }^{* *} Y=60,244+1,3813 X ; R 2=0,8077$

Tabela 3: Desempenho, composição do leite e eficiência de uso do nitrogênio $(\mathrm{N})$ dietético por vacas F1 Holandês $x$ Zebu alimentadas com dietas contendo níveis crescentes de NNP, coeficientes de variação (CV), média geral e valor real de $P$

\begin{tabular}{|c|c|c|c|c|c|c|c|}
\hline \multirow[b]{2}{*}{ Itens } & \multicolumn{4}{|c|}{ Níveis de PB na forma de NNP (\%) } & \multirow[b]{2}{*}{ CV (\%) } & \multirow[b]{2}{*}{ Média Geral } & \multirow[b]{2}{*}{$\mathrm{Pr}>\mathrm{Fc}$} \\
\hline & 0 & 0,92 & 1,84 & 2,77 & & & \\
\hline Peso inicial, $\mathrm{kg}$ & 427 & 426 & 429 & 426 & 2,03 & 427 & 0,8532 \\
\hline Peso final, $\mathrm{kg}$ & 430 & 433 & 430 & 428 & 1,53 & 430 & 0,6262 \\
\hline Ganho de peso no período, kg & 2,63 & 6,69 & 1,19 & 2,44 & 3,30 & 3,23 & 0,4444 \\
\hline Escore corporal & 3,06 & 3,00 & 3,00 & 3,00 & 2,93 & 3,01 & 0,2988 \\
\hline Produção de leite, $\mathrm{kg} \mathrm{dia}^{-1}$ & 8,07 & 8,51 & 8,13 & 8,06 & 4,29 & 8,19 & 0,0648 \\
\hline${ }^{1}$ Produção de leite, $\mathrm{kg} \mathrm{dia}^{-1}$ & 9,97 & 10,3 & 9,93 & 9,92 & 4,90 & 10,0 & 0,3889 \\
\hline Gordura do leite, $\%$ & 4,99 & 4,86 & 4,90 & 4,93 & 6,60 & 4,92 & 0,5264 \\
\hline Proteína do leite, $\%$ & 3,43 & 3,46 & 3,36 & 3,29 & 6,34 & 3,39 & 0,4035 \\
\hline${ }^{2} \mathrm{NUL}, \mathrm{mg} \mathrm{dL}^{-1}$ & 7,14 & 8,80 & 11,04 & 11,32 & 13,33 & * & 0,0000 \\
\hline \multirow[t]{2}{*}{ Conversão alimentar } & 1,33 & 1,26 & 1,33 & 1,39 & 8,22 & 1,32 & 0,5587 \\
\hline & \multicolumn{3}{|c|}{ Eficiência } & & & & \\
\hline Eficiência alimentar & 0,75 & 0,79 & 0,75 & 0,71 & 9,01 & 0,75 & 0,6778 \\
\hline Consumo N, g dia ${ }^{-1}$ & 174 & 168 & 171 & 187 & 15,6 & 175 & 0,2549 \\
\hline $\mathrm{N}$ no leite, $\mathrm{g} \mathrm{dia}^{-1}$ & 43,3 & 46,1 & 42,8 & 41,5 & 3,91 & 43,4 & 0,3887 \\
\hline${ }^{3}$ Eficiência de uso $\mathrm{N}$ & 0,25 & 0,27 & 0,25 & 0,22 & 0,02 & 0,25 & 0,7782 \\
\hline
\end{tabular}


Tabela 4: Efeito no custo do concentrado pela inclusão de níveis de ureia em dietas de vacas F1 Holandês $x$ Zebu

\begin{tabular}{lcccc}
\hline \multirow{2}{*}{\multicolumn{1}{c}{ Itens }} & \multicolumn{4}{c}{ Níveis de PB na forma de NNP (\%) } \\
\cline { 2 - 5 } & 0 & 0,92 & 1,84 & 2,77 \\
\hline${\text { Consumo, } \text { kg dia }^{-1}}_{\text {Custo, } \mathrm{R} \$ \mathrm{~kg} \mathrm{de} \mathrm{MS}^{-1}}$ & 2,67 & 2,67 & 2,67 & 2,67 \\
Custo total, $\mathrm{R} \$$ vaca dia $^{-1}$ & 3,13 & 0,96 & 0,90 & 0,85 \\
Aumento do custo* & 3,02 & 2,57 & 2,40 & 2,27 \\
\hline
\end{tabular}

*Aumento em relação a dieta de menor custo $(2,77 \%$ de PB na forma de NNP na dieta)

Considerando o preço do quilo de proteína bruta da ureia em relação ao farelo de soja ou de qualquer outro concentrado proteico de origem animal ou vegetal, a relação será, por muito tempo ainda, favorável à ureia, dado ao efeito de mercado. Em uma reflexão direta da cadeia agroindustrial do leite, no âmbito da produção primária de leite, é constituída por pequenos produtores heterogêneos quanto à tecnificação, estabelecendo unidades de produção com diferentes produtividades. A característica comum é que os produtores são tomadores de preço por natureza, ficando como opção para busca da lucratividade através do aumento da produção de leite ou redução dos custos de produção, sendo a substituição total do farelo de soja pela ureia, especialmente na dieta de vacas mestiças, uma opção técnica para tornar o produto competitivo.

\section{Conclusões}

A substituição total do farelo de soja pela ureia na dieta de vacas primíparas F1 Holandês/Zebu, não modifica os parâmetros digestivos dos animais, mantém o escore da condição corporal, permite o uso do nitrogênio de forma eficiente e é economicamente viável em relação ao uso de farelo de soja, para uma produção média de $10 \mathrm{~kg}$ de leite dia $^{-1}$.

\section{Agradecimentos}

À FAPEMIG pelo auxílio financeiro; ao CNPq e Capes pelo auxílio com bolsas.

\section{Referências}

ALVAREZ, E.G.A.; HUNTINGTON, G.B.; BURNS, J.C. Effects of supplemental urea sources and feeding frequency on ruminal fermentation, fiber digestion, and nitrogen balance in beef steers. Animal Feed Science and Technology, v. 171, n. 2, p. 136-145, 2012.

ALVES, A.F.; ZERVOUDAKIS, J.T.; ZERVOUDAKIS, L.K.H.; CABRAL, L.S.; LEONEL, F.P.; PAULA, N.F. Substituição do farelo de soja por farelo de algodão de alta energia em dietas para vacas leiteiras em produção: consumo, digestibilidade dos nutrientes, balanço de nitrogênio e produção leiteira. Revista Brasileira de Zootecnia, v. 39, n. 3, p. 532-540, 2010.

ANTUNES, A.P.S.; ROCHA JÚNIOR, V.R.; RUAS, J.R.M.; CALDEIRA, L.A.; OLIVEIRA, L.M.; SOUZA, V.M., SOUZA, C.F.; SILVA, D.A. Characteristics of the ingestive behavior and milk production of $\mathrm{F} 1$ Holstein $\mathrm{x}$ Zebu cows fed with diets containing increasing levels of urea. Revista Brasileira de Ciência Veterinária, v. 21, n. 3, p. 192-198, 2014.

BRODERICK, G.A. Effects of varying dietary protein and energy levels on the production of lactating dairy cows. Journal of Dairy Science, v. 86, n. 4, p. 1370-1381, 2003.

CASALI, A.O.; DETMANN, E.; VALADARES FILHO, S.C.; PEREIRA, J.C.; HENRIQUES, L.T.; FREITAS, S.G.; PAULINO, M.F. Influência do tempo de incubação e do tamanho de partículas sobre os teores de compostos indigestíveis em alimentos e fezes bovinas obtidos por procedimentos in situ. Revista Brasileira de Zootecnia, v. 37, n. 2, p. 335-342, 2008.

FERREIRA, D. F. Sisvar: um computador sistema de análise estatística. Ciência e Agrotecnologia, v. 35, n. 6, p. 1039-1042, 2011.

GONÇALVES, G.S.; PEDREIRA, M.S.; AZEVEDO, J.A.G.; DEL REI, A.J.; SILVA, H.G.O.; SILVA, F.F. Replacement of soybean meal by conventional and coated urea in dairy cows: intake, digestibility, production and composition of milk. Acta Scientiarum Animal.Sciences, v. 36, n. 1, p. 71-78, 2014.
LAGUNA, J.G.; RODRIGUES, A.N.; SATURNINO, H.N.; RUAS, J.R.M.; COELHO, S.G.; REIS, R.B. Alimentação de vacas F1 Holandês $x$ Zebu com suplementos nitrogenados e monensina sódica: avaliação do consumo, parâmetros ruminais e produção de leite. Arquivo Brasileiro de Medicina Veterinária e Zootecnia, v. 65, n. 3, p. 841-846, 2013.

LIMA, F.H.S.; NETO, S.G.; LEITE, S.V.F.; MELO, A.S: SOUSA, J.E.L.; MOURA, J.F.P.; LIMA, J.S.B.; COSTA, T.P. Comportamento ingestivo de vacas primíparas das raças Guzerá e Sindi recebendodietas com diferentes níveis de ureia. Ciência Rural, v .43, n. 4, p.709-715, 2013.

LOPES, P.F.; REIS, R.P.; YAMAGUCHI, L.C.T. Custos e escala de produção na pecuária leiteira: estudo nos principais estados produtores do Brasil. Revista de Economia e Sociologia Rural, v. 45, n. 3, p. 567-590, 2007.

MIGLIOR, F.; SEWALEM, A.; JAMROZIK, J.; BOHMANOVA, J.; LEFEBVRE, D.M.; MOORE, R.K. Genetic analysis of milk urea nitrogen and lactose and their relationship with other production traits in Canadian Holstein cattle. Journal of Dairy Science, v. 90, n. 5, p. 2468-2479, 2007.

MUCHA, S.; STRENDBERG, E. Genetic analysis of milk urea nitrogen and relationships with yield and fertility across lactation. Journal of Dairy Science, v. 94, n.11, p. 5665-5672, 2011.

National Research Counsil. Nutrient requirements of dairy cattle. 7. ed. Washington, 381 p., 2001.

PAIXÃO, M.L.; VALADARES FILHO, S.C.; LEÃO, M.I.; VALADARES, R.F.D.; PAULINO, M.F.; MARCONDES, M.I.; SILVA, P.A.; PINA, D.S. Ureia em dietas para bovinos: consumo, digestibilidade dos nutrientes, ganho de peso, características de carcaça e produção microbiana. Revista Brasileira de Zootecnia, v. 35, n. 6, p. 2451-2460, 2006.

PESSOA, R.A.S.; LEÃO, M.I.; FERREIRA, M.A.; VALADARES FILHO, S.C.; VALADARES, R.F.D.; QUEIROZ, A.C. Balanço de compostos nitrogenados e produção de proteína microbiana em novilhas leiteiras alimentadas com palma forrageira, bagaço de cana-de-açúcar e ureia associados a diferentes suplementos. Revista Brasileira de Zootecnia, v. 38, n. 5, p. 941-945, 2009. 
PINA, D.S.; VALADARES FILHO, S.C.; VALADARES, R.F.D.; CAMPOS, J.M.; DETMANN, E.; MARCONDES, M.I.; OLIVEIRA, A.S.; TEIXEIRA, R.M.A. Consumo e digestibilidade aparente total dos nutrientes, produção e composição do leite de vacas alimentadas com dietas contendo diferentes fontes de proteína. Revista Brasileira de Zootecnia, v. 35, n. 4, p.1543-1551, 2006.

RENNÓ, F.P.; PEREIRA, J.C.; LEITE C.A.M.; RODRIGUES, M,T.; CAMPOS, O.F.; FONSECA, D.M.; RENNÓ, L.N. Eficiência bioeconômica de estratégias de alimentação em sistemas de produção de leite. 1. Produção por animal e por área. Revista Brasileira de Zootecnia, v. 37, n. 4, p. 743-753, 2008.

RUAS, J.R.M.; FERREIRA, J.J.; SILVA, E.A.; MENEZES, A.C.; BRANDÃO, F.Z.; SANTOS, M.D.; CARVALHO, B.C. Desempenho de bezerros filhos de vacas F1 Holandês Zebu submetidas a diferentes sistemas de alimentação e manejo. Revista Brasileira de Ciência Veterinária, v.16, n. 8, p. 68-72, 2009.

RUAS, J.R.M.; SILVA, E.A.; QUEIROZ, D.S.; PEREIRA, M.E.G.; SOARES JÚNIOR, J.A.G.; SANTOS, M.D.; ROCHA JÚNIOR, V.R.; Costa, M.D. Características produtivas da lactação de quatro grupos genéticos F1 Holandês x Zebu. Revista Brasileira de Ciência Veterinária, v. 21, n. 1, p. 33-37, 2014.

SANTOS, S.A.; VALADARES FILHO, S.C.; DETMANN, E.; VALADARES, R.F.D.; RUAS, J.R.M.; PRADOS, L.F., AMARAL, P.M.; MARIZ, L.D.S. Intake, digestibility and nitrogen use efficiency in crossbred F1 Holstein x Zebu grazing cows. Revista Brasileira Zootecnia, v. 41, n. 4, p.1025-1034, 2012.

SILVA, A.E.M.; LIRA, A.T.; FERREIRA, M.A.; BARROS, L.J.A.; MELO, T.T.B.; SIQUEIRA, T.D.Q.; SOARES, L.F.P.; COSTA, C.T.F. Bagaço de cana-de-açúcar como volumoso exclusivo em dietas para ovinos. Revista Brasileira de Saúde e Produção Animal, v. 16, n. 1, p.118-129, 2015.

SINCLAIR K. D.; GARNSWORTHY, P.C.; MANN, G.E.;

SINCLAIR, L.A. Reducing dietary protein in dairy cow diets: implications for nitrogen utilization, milk production, welfare and fertility. Animal, v. 8, n. 2, p. 262-274, 2014.
SINCLAIR, L.A.; BLAKE, C.W.; GRIFFIN, P.; JONES, G.H. The partial replacement of soya bean meal and rapeseed meal with feed grade urea or a slow-release urea and its effect on the performance, metabolism and digestibility in dairy cows. Animal, v. 6 n. 6 , p. 920-927, 2012.

SKLAN, D.; KAIM, M.; MOALLEM, U.; FOLMAN, Y. Effect of dietary calcium soaps on milk yield, body weight, reproductive hormones, and fertility in first parity and older cows. Journal of Dairy Science, v. 77, n. 6, p. 1652-1660, 1994.

STOOP, W.M.; BOVENHUIS, H.; VAN ARENDONK, J.A.M. Genetic parameters for milk urea nitrogen in relation to milk production traits. Journal of Dairy Science, v.90, n. 4, p.19811986, 2007.

VALADARES FILHO, S.C.; BRODERICK, G.A.; VALADARES, R.F.D.; CLAYTON, M. K. Effect of replacing alfalfa silage with high moisture corn on nutrient utilization and milk production. Journal of Dairy Science, v. 83, n.1, p. 106-114, 2000.

WANAPAT, M.; POLYORACH, S.; BOONNOP, K.; MAPATO, C.; CHERDTHONG, A. Effects of treating rice straw with urea or urea and calcium hydroxide upon intake, digestibility, rumen fermentation and milk yield of dairy cows. Livestock Science, v. 125 , p. 238-243, 2009.

WILDMAN, E.E.; JONES, G.M.; WAGNER, P.L; BOMAN, R.L. A dairy condition scoring system and its relationship to selected production characteristics. Journal of Dairy Science, v. 65, n. 3, p. 495-498, 1982.

WILSON, G.; MARTZ, F.A.; CAMPBELL, J.R.; BECKER, B.A. Evaluation of factors responsible for reduced voluntary intake of urea for ruminants. Journal of Animal Science, v. 41, n. 5, p. 14311437, 1975. 